\title{
Scabies in Koranic schools in Dakar, Senegal: Comparison of two therapeutic modalities
}

\author{
Ly Fatimata ${ }^{1,2}$, Faye Adama ${ }^{3}$, Wone Issa ${ }^{4}$, Lelo Souleye ${ }^{5}$, Diouf Astou ${ }^{1}$, Koundio Abou ${ }^{6}$, \\ Ndiaye Diop Mame Tene ${ }^{1}$, Gueye Diagne Fatou ${ }^{1}$, Deh Aminata ${ }^{1}$, Faye Babacar ${ }^{5}$, Toure Fall \\ Awa Oumar ${ }^{6}$, Mahe Antoine ${ }^{7}$, and Tall Dia Anta ${ }^{8}$ \\ ${ }^{1}$ Dermatology/STI, EPS 1 Institut d'Hygiène Sociale de Dakar, Senegal \\ 2University Cheikh Anta Diop of Dakar, Senegal \\ ${ }^{3}$ Department of Public Health, University Cheikh Anta Diop of Dakar, Senegal \\ ${ }^{4}$ University Assane Seck de Ziguinchor, Senegal \\ ${ }^{5}$ Department of Parasitology-Mycology, University Cheikh Anta Diop, Dakar, Senegal \\ ${ }^{6}$ Laboratory of Hematology, National Teaching Hospital Aristide Le Dantec, Dakar, Senegal \\ ${ }^{7}$ Hôpital Louis Pasteur, Colmar, France \\ ${ }^{8}$ ISED Institut Sante et Développement, Mbour, Senegal
}

Doi: https://dx.doi.org/10.36685/phi.v7i4.456

Received: 14 August 2021 | Revised: 18 November 2021 | Accepted: 7December 2021

Corresponding author:

Ly Fatimata

BP 5825 Dakar Université Cheikh Anta Diop of Dakar

Email: lyfaty@gmail.com/fatimata.ly@ucad.edu.sn

Copyright: @ 2021 the author(s). This is an open-access article distributed under the terms of the Creative Commons Attribution Non-Commercial License, which permits unrestricted non-commercial use, distribution, and reproduction in any medium provided the original work is properly cited.

\section{Abstract}

Background: In 2017, WHO recognized scabies as a neglected tropical disease. The optimal treatment is not well defined in some communities.

Objective: This study aimed to compare ivermectin and benzyl benzoate in the treatment of scabies in Koranic schools (or "daara") in Dakar (region).

Methods: This was a prospective randomized trial conducted from January to October 2018 in Senegal. Any resident living in the selected "daara" and diagnosed with scabies was included. The administered treatments were benzyl benzoate (BB) or ivermectin. At the outset, if one case of scabies was diagnosed, all residents received treatment. Ivermectin was given at the dose of $200 \mu \mathrm{g} / \mathrm{kg}$. The same treatment was repeated on day 7 for each group, the endpoint was at D14, and the data were analyzed with STATA 14.

Results: Fifteen "daara" were included. Of the 959 residents, 70 were diagnosed with scabies: prevalence of $7.29 \%$. All patients except one were male; the mean age was 9.98 years (4-17). At D14, in the BB arm, cure rate was $42.85 \%(n=15)$ while in the ivermectin arm, this rate was $5.71 \%(n=2)$ with a significant difference $(p=0.01)$. On D28, the cure rate was still higher in the BB group $57.14(n=20)$ versus ivermectin $21.42(n=6)$ with a significant difference $(p=0.004)$. On $D 42$, all patients except eight were cured. At D14, we found a link between the cure rate, the number of people in the room $(p=0.01)$, and the number of showers per week ( $p$ $=0.01)$ but no link with the number of people per "daara" $(p=0.163)$. At $D 28$, we found a link between the cure rate, the number of people sleeping in the room $(p=0.03)$, and the number of showers per week $(p=$ $0.01)$ but not with the number of people per "daara" $(p=0.07)$.

Conclusion: In Koranic schools, the cure rate is higher with benzyl benzoate compared to ivermectin.

Keywords: scabies; ivermectin; benzyl benzoate; koranic school; Senegal; prospective studies 


\section{Background}

Scabies is an ectoparasitosis caused by Sarcoptes scabiei var. hominis that may reach epidemic levels in some regions. In 2017, WHO recognized it as a neglected tropical disease (NTD) (World Health Organization, 2017). The Global Burden of Diseases study estimates that scabies affects 455 million persons worldwide each year, leading to approximately 3.8 million Disability-Adjusted LifeYears (DALYs), making scabies one of the most common NTDs (Lipton et al., 2016; Karimkhani et al., 2017).

The most common treatment used in sub-Saharan Africa is benzyl benzoate in French-speaking countries and permethrin in English-speaking countries. Ivermectin by the oral route is also used, but the availability is limited, and the response is variable (Ly et al., 2009). Mass treatment for scabies has been shown to be effective in some communities. Indeed, the SHIFT study conducted in the Fiji Islands over a period of one year, including 2051 patients, showed a significant reduction in the prevalence of scabies after mass treatment (Romani et al., 2015). In this study, three groups were randomized and received either standard treatment (with topical permethrin for the patient and contacts) in a health center $(n=803)$ or ivermectin $(n=716)$, or mass treatment with permethrin $(n=532)$; in all three groups, a relative reduction in the prevalence of scabies was observed up to 12 months. This decrease in prevalence was significantly greater in the ivermectin group than in the permethrin group (94\% versus $62 \%$ ). In addition, a reduction in the prevalence of impetigo was observed in the different groups, especially in the ivermectin group.

In Dakar, in a randomized therapeutic trial, we had shown the superiority previously in terms of efficacy of benzyl benzoate compared to ivermectin in the treatment of common scabies (Ly et al., 2009). Our aim in this new study was to compare ivermectin and benzyl benzoate in the treatment of scabies in Koranic schools in the Dakar region.

\section{Methods}

\section{Study Design}

This was a prospective randomized controlled clinical trial conducted from January to October 2018.

\section{Setting}

Senegal population is 15.7 million. The population growth is 2.9, the life expectancy is 66.7 years, and the literacy rate (for 15 years and over) is $55.6 \%$. The main religion is Islam (94\%), and the human development index is $162^{\text {nd }}$ out of 188 countries. The capital of Senegal is Dakar (550 km2), with a population of 3835019 inhabitants (Cnltp, 2018). Dakar region has four departments: Dakar, Pikine, Guediawaye and Rufisque. One thousand and six Koranic schools ("Daaras", Franco-Arab school, and Arab school) have been listed in the Dakar region, with a majority in the departments of Pikine and Dakar. The total number of residents in the "daara" has been estimated at 42,162 . Koranic schools are generally housed in houses in good condition (44\%), houses under construction (19\%), mosques (13\%), and houses abandoned by their owners (5\%) (Cnltp, 2018).

\section{Population}

A case was defined by the following clinical characteristics: itching that affected at least three distinct sites of the body and characteristic lesions (vesicles, papules, nodules, or pustules) located in at least three sites of predilection for scabies (interdigital folds of the hands, elbows, wrists, buttocks, axillary folds, nipple areolae in girls and male external genitalia), as assessed by a trained health worker.

Parasitological examination: the scales were obtained by scraping the skin with a scalpel blade. A drop of potassium hydroxide (10\%) was placed on the collected material to facilitate the reading of the slide, and then the slide was covered with a coverslip. The systematic sites of harvest were the interdigital spaces, the anterior surfaces of the wrists, and the buttocks. A parasitological sample was taken, whatever the number of sites, in an attempt to confirm the diagnosis.

In this study, we were provided with a list of Koranic schools established by the heads of health districts and the academic inspectorate. The Koranic schools in two departments (Dakar and Pikine) were randomly selected. The choice of schools was random, on the basis of a list drawn up by the academic authorities, according to the locality, and which included the telephone number of the head of the school. The head of school was contacted by telephone to check whether the category was that of 
boarding or day school. Then if the school was eligible, it was chosen. If permission for the study was refused or the school closed, we moved to the next school on the list. Questions asked included variables such as consumer goods and type of accommodation. For each resident of a selected school, at least five visits were carried out (day 1-714-21-28). Those who were diagnosed with scabies were followed until they had healed. The treatment was based on benzyl benzoate or ivermectin.

\section{Inclusion criteria}

We selected only schools with boarding pupils. Any resident living in the chosen Koranic school and diagnosed with scabies were included regardless of age and sex. Authorization was previously requested and obtained from the head of the Koranic school. A consent form was submitted and signed. There were no exclusion criteria

\section{Study variables}

Specialists and students in dermatology collected data with a pre-established tested and validated questionnaire. The socio-demographic characteristics of school children (age, sex, number of residents in the school and the neighborhood, socioeconomic level, and education level) were recorded. We also collected the clinical variables: weight, size, BMI, blood pressure, brachial perimeter, type and localization of the lesions, the comorbidities, urine dipstick in case of edema or hematuria, the results of laboratory examinations (hemogram, skin parasitological examination, and stools parasitological exam, mycology).

\section{Interventions}

The administered treatments were benzyl benzoate or ivermectin. In the Koranic School, all patients received the same treatment. At the outset, if one case of scabies were diagnosed, all residents would receive treatment. Benzyl benzoate was applied over the whole body, except the face, and left for 24 hours after taking a shower with soap. Ivermectin was given at the dose of $200 \mu \mathrm{g} / \mathrm{kg}$ in a single dose rounded to the nearest whole or half $3 \mathrm{mg}$ tablet were given. The same treatment was repeated on day 7 for each group. The endpoint was at D14. All patients, administrative staff, and teachers living in the Koranic School received the same treatment. Hygiene measures, washing, and ironing clothes and bedding were also recommended. If impetigo was present, patients also received antibiotics (amoxicillin or josamycin) and antiseptics (polyvidone iodine) before the treatment of scabies. If anemia was diagnosed, ferrous fumarate was given. All other comorbidities were treated.

Patients were followed on D7, 14,21,28 until their complete recovery, and the side effects were recorded. The healing criteria were as follows: the disappearance of the pruritus and clinical lesions. If the patients were not cured on D14, the same treatment was repeated, and in the event of no cure on D28, a switch to the other treatment was performed. The cure was defined as the absence of pruritus and lesions.

\section{Data Analysis}

The data were entered and analyzed with the STATA software version 14 . We determined the mean, median, and standard deviation for quantitative variables. For qualitative variables, the Chi-square and Fisher tests were used for the comparison of percentages with a level of the signification of $5 \%$.

\section{Ethical Consideration}

This study was conducted according to the declaration of Helsinki and existing national legal and regulatory requirements. The protocol was reviewed and approved by the Ethics committee of Dakar University. The approval number was 0258/2017/CER/UCAD. Informed signed consent of the child's legal representative was required prior to participation in the study. To respect confidentiality, an identification code was given to each participant.

\section{Results}

From January 9 to October 16, 2018, fifteen koranic schools were included. Of the 959 residents, 70 were diagnosed with scabies, giving a prevalence of $7.29 \%$. All patients except one were male; the mean age was 9.98 years (4-17). Students reported that their parents owned a home in $71.42 \%$ of cases while they were tenants in $20 \%$ of cases. We recorded the therapeutic details, type of treatment prescribed, adherence, primary endpoint (cure or persistence of infestation), and secondary endpoints (side effects). Treatment received: 35 patients were treated with ivermectin, while 35 received benzyl benzoate (Table 1 and 2). 
Table 1 Distribution of treatment allocated according to the Koranic school

\begin{tabular}{lllll}
\hline School & Number of cases & Number of residents & Frequency & Treatment allocated \\
\hline Daara 2 & 01 & 13 & 7.69 & Benzyl benzoate \\
Daara 3 & 01 & 23 & 4.34 & Ivermectin \\
Daara 5 & 07 & 51 & 13.72 & Ivermectin \\
Daara 6 & 33 & 107 & 30.84 & Benzyl benzoate \\
Daara 7 & 01 & 47 & 2.12 & Ivermectin \\
Daara 14 & 01 & 61 & 1.63 & Benzyl benzoate \\
Daara 15 & 26 & 328 & 7.92 & Ivermectin \\
\hline
\end{tabular}

Table 2 Distribution of the patients according to the treatment and the follow-up

\begin{tabular}{llll}
\hline & Benzyl benzoate & Ivermectin & Total \\
\hline Participated & 35 & 35 & 70 \\
Follow up until D28 & 35 & 28 & 63 \\
Cured at D14 & 15 & 2 & 17 \\
Cured at D28 & 20 & 6 & 26 \\
\hline
\end{tabular}

The average dose of ivermectin was $6428.571 \mu \mathrm{g}$ (3000 - 9000). The number of ivermectin tablet doses per patient was $1(n=1), 2(n=28)$ or $3(n=6)$. On D 14 the global cure rate was $24.29 \%(n=17)$ and on D21 36.3\% $(n=25)$, on D $2841.27 \%(n=26)$. On D 42 we found a global cure rate of $75.76 \%$ (Table 3).

Table 3 comparison of cure rates of patients with scabies by treatment

\begin{tabular}{lllll}
\hline & Yes & No & Total & p-value \\
& $\mathbf{n}(\%)$ & $\mathbf{n}(\%)$ & & p $=0.0001$ \\
\hline Cured D14 & & & & \\
Benzyl Benzoate & $15(88.24)$ & $20(37.74)$ & 35 & \\
Ivermectin & $2(11.76)$ & $33(62.26)$ & 35 & \\
Total & 17 & 53 & 70 & $\mathrm{p}=0.004$ \\
\hline Cured D28 & & & & \\
Benzyl benzoate & $20(76.92)$ & $15(40.54)$ & $35(55.56)$ & \\
Ivermectin & $6(23.08)$ & $22(59.46)$ & $28(44.44)$ & \\
Total & 26 & 37 & 63 & \\
\hline
\end{tabular}

When we compare the cure rates at D14, in the benzyl benzoate arm, this rate is $42.85 \%(n=15)$, while in the ivermectin arm, this rate is $5.71 \%(n=2)$ with a significant difference $(p=0.0001)$. On D 28, the cure rate was still higher in the benzyl benzoate group ( $p=0.004$ ). We represented in Table 3 the cure rate according to the treatment allocated and in Table $\mathbf{4}$ and $\mathbf{5}$ the factors associated with the cure.

On D28, the patients who were not cured were switched to the benzyl benzoate group. On D42, all patients except eight were cured. The compliance was poor in $40.98 \%$ of patients on D7 and $11.63 \%$ on D14. We found the following side effects: nausea ( $\mathrm{n}$
$=1)$ and vomiting $(n=1)$ or abdominal pain $(n=3)$ in the ivermectin group or irritant dermatitis $(n=9)$ and contact eczema $(n=1)$ in the benzyl benzoate group. There was no difference in the cure rate as a function of compliance $(p=0.05)$, age $(p=0.52)$, type of habitat $(p=0.67)$ or the existence of household goods consumption $(p=0.23)$. We also did not find a relationship between the cure rate and the existence of secondary infection $(p=0.59)$.

On day 14 , we found a link between the cure rate, the number of people in the room $(p=0.01)$, and the number of showers per week ( $p=0.01)$ but no link with the number of people per "daara" $(p=0.163)$. 
Table 4 Factors associated with the cure rate at day 14

\begin{tabular}{|c|c|c|c|}
\hline & \multicolumn{3}{|c|}{ Recovery Day 14} \\
\hline & $\begin{array}{l}\text { Yes } \\
\text { n (\%) }\end{array}$ & $\begin{array}{l}\text { No } \\
\text { n (\%) }\end{array}$ & $p$-value \\
\hline Age & & & 0.017 \\
\hline$<10$ years & $3 / 15(20)$ & $27 / 49(55.1)$ & \\
\hline$\geq 10$ years & $12 / 15(80)$ & $22 / 49(44.9)$ & \\
\hline Number of showers per week & & & 0.011 \\
\hline 1 & 9/17 (52.9) & $11 / 44(25)$ & \\
\hline 2 & $4 / 17(23.5)$ & $4 / 44(9.1)$ & \\
\hline$>2$ & $4 / 17(23.5)$ & $29 / 44(65.9)$ & \\
\hline Number of people in the room & & & 0.012 \\
\hline $1-10$ & $0 / 17(0.0)$ & $17 / 45(37.8)$ & \\
\hline$>10$ & $17 / 17(100)$ & $28 / 45(62.2)$ & \\
\hline Number of residents per Daara & & & 0.163 \\
\hline$\leq 30$ & $1 / 17(5.9)$ & $1 / 27(3.7)$ & \\
\hline $31-60$ & $1 / 17(5.9)$ & $8 / 27(29.6)$ & \\
\hline $61-328$ & $15 / 17(88.2)$ & $18 / 27(66.7)$ & \\
\hline
\end{tabular}

Table 5 Factors associated with the cure rate at day 28

\begin{tabular}{|c|c|c|c|}
\hline & \multicolumn{3}{|c|}{ Recovery Day 28} \\
\hline & $\begin{array}{l}\text { Yes } \\
\text { n (\%) }\end{array}$ & $\begin{array}{l}\text { No } \\
\text { n (\%) }\end{array}$ & p-value \\
\hline Age & & & 0.081 \\
\hline$<10$ years & $7 / 22(31.8)$ & $23 / 42(54.8)$ & \\
\hline$\geq 10$ years & $15 / 22(68.2)$ & $19 / 42(45.2)$ & \\
\hline Number of showers per week & & & 0.012 \\
\hline 1 & $12 / 23(52.2)$ & $8 / 38(21.1)$ & \\
\hline 2 & 4/23 (17.4) & 4/38 (10.5) & \\
\hline$>2$ & $7 / 23(30.4)$ & $26 / 38(68.4)$ & \\
\hline Number of people in the room & & & 0.032 \\
\hline $1-10$ & 2/23 (8.7) & $5 / 39(12.8)$ & \\
\hline$>10$ & $21 / 23(91.3)$ & $24 / 39(61.5)$ & \\
\hline Number of residents per Daara & & & 0.076 \\
\hline$\leq 30-60$ & 4/22 (18.2) & $7 / 22(31.8)$ & \\
\hline $61-328$ & $18 / 22(81.8)$ & $15 / 22(68.2)$ & \\
\hline
\end{tabular}

On day 28 , we found a link between the cure rate, the number of people sleeping in the room $(p=0.03)$, and the number of showers per week $(p=0.01)$ but not with the number of people per "daara" $(p=0.07)$.

For the comorbidities, overall, $22.7 \%$ (105/463) of the children were found infected with at least one intestinal parasite species. Intestinal parasites were mainly represented by protozoan parasites $(44.76 \%)$ and helminth parasites (41.9\%). Association between protozan and helminth parasites was observed in $13.33 \%$. Anemia was found in $11.7 \%$ of residents, and pediculosis was found in $2.94 \%$ (n $=17$ ), exclusively in girls.

\section{Discussion}

We reported the results of a study comparing two modalities of mass treatment of scabies in student residents of Koranic schools. We compared benzyl benzoate to oral ivermectin. The difficulty in performing a double-blind trial is that one of the treatments is administered orally (ivermectin) while the other is a topical treatment (benzyl benzoate). In our study, we alternately allocated the treatments in each of the Koranic schools that we included. This may have introduced a selection bias. However, the treatments were evenly divided between the two arms. If a single case of scabies was diagnosed, all residents and support staff were also treated. 
Similarly, hygienic measures (washing and ironing of clothes, disinfection of bedding) were recommended for all patients. In Senegal, benzyl benzoate is the standard treatment, and ivermectin is not marketed in health facilities or pharmacies; hospital practitioners can obtain it as a donation. In addition to its proven efficacy in scabies, it is also active against lice (del Giudice et al., 2003), helminthiases (Palmeirim et al., 2018), recently, potentially on SARS-COV2 (Kaur et al., 2021). In our study, the prevalence of pediculosis was $2.94 \%$, while gastrointestinal parasitosis was found in nearly a quarter of the residents. Ivermectin, therefore, has a triple therapeutic benefit, especially as almost $11.7 \%$ of patients presented with anemia. However, we know that the main cause of anemia is digestive parasitosis (Lemoine \& Tounian, 2020).

Further studies will determine the impact of ivermectin on parasitic digestive diseases and pediculosis in the koranic schools. The cure rate found in our study was very low, with less than a quarter of the patients who were cured on D14, while at D28, less than half of the patients were cured. In a based hospital study conducted by Sule and Thacher (2007), the overall cure rate after four weeks was $95 \%$ in the ivermectin group and $86 \%$ in the topical treatment group $(p=0.04)$. This highlights the therapeutic difficulties of managing scabies in communities such as Koranic schools. In our study, treatment with benzyl benzoate was shown to be significantly superior in terms of effectiveness. Indeed, on D14, only two patients in the ivermectin group were cured against 17 in the benzyl benzoate group. There are many possible reasons for the low cure rate with ivermectin: low number of patients, promiscuity with overcrowded conditions, and environmental factors.

In our study, the number of patients is relatively low; a total of 70 patients were included. In most studies, the number of patients is higher, so the power of these studies is very important. The promiscuity could constitute a risk factor for recontamination. Our research found no case of crusted scabies that can be a source of reinfection. Ivermectin is not ovicidal, and both the treatment with benzyl benzoate and ivermectin was renewed after a week to obtain an optimal response. Use of higher doses of ivermectin at $400 \mu \mathrm{g} / \mathrm{kg}$ may promote healing (Navarro et al., 2020). It is possible that ivermectin does not work in overcrowded conditions as there is the risk of reinfection from fomites or other children.

In our study, the hygiene measures and disinfection are not optimal. Therefore, it is necessary to train those in charge and residents of Koranic schools for the effective application of hygiene and disinfection measures to reduce the risk of recontamination. This strategy has shown its effectiveness in koranic schools in Bangladesh. The best results with ivermectin have been obtained in trials carried out on islands - poorer results, including Australia, have been seen in land-based or city settings (Gwee et al., 2020).

However, recently (personal communication July 2021), as part of an investigation of an outbreak of scabies in a Koranic school, we included 72 patients, all were male. The majority of patients were children $(90.30 \%)$ aged less than 15 years. The adults $(n=7)$ were 15 to 45 years old. The main conditions found were as follows: 64 cases of scabies were confirmed according to the 2020 criteria of IACS (International Alliance for the Control of Scabies). After administration of two doses of ivermectin $(200 \mu \mathrm{g} / \mathrm{kg})$, all the 65 patients who were evaluated were completely cured. But it was the first outbreak in this koranic school, and hygiene and disinfection measures were observed. We believe that the conditions of use and the environment influence the effectiveness of ivermectin.

In a 2007 Cochrane meta-analysis, the superiority in terms of efficacy of benzyl benzoate was found in two studies, while ivermectin was found to be more effective than benzyl benzoate in three studies (Strong \& Johnstone, 2007). However, these different studies were very heterogeneous: for instance, the endpoints were variable either on D7, D14, or M1. The difference between these studies and ours lies in the fact that the first was carried out in patients selected from hospital consultations, while in our study, the patients were residents in closed communities. The crowded living conditions and the number of borders are the main reasons for the treatment failure in scabies known as "the sevenyear-old itch" (Talukder et al., 2013). Moreover, in some Koranic schools, a real epidemic was present with the prevalence of more than $10 \%$ sometimes. Thus, in the "daaras", 6 and 15, the prevalence was $13.72 \%$ and $30.84 \%$, respectively. 
The therapeutic difficulty is also linked to poor compliance since the poor compliance rate was $40.98 \%$ on Day 7 , while it was $11.63 \%$ on D14. However, there was no statistically significant association between poor compliance and cure rate on Day 14 or Day 28. In our study, treatment compliance had improved considerably over the weeks because, at each visit, we repeated the explanations, which made it possible to achieve a $95.5 \%$ good compliance rate by Day 28 . We carried out mass treatment administration; indeed, if a single case of scabies was diagnosed, all residents were treated and followed for at least four weeks. Patients in whom the signs of scabies persisted were followed up to Day 42. However, this strategy proves costly for a country with limited economic resources. Hence the interest in carrying out studies to determine optimal therapeutic strategy. However, with the design that we had adopted, we did not identify any new cases of infestation among the students of the Koranic schools selected.

Mass treatment has been shown to be effective in reducing the prevalence of scabies by more than $50 \%$ in a study conducted in Bangladesh, which aimed to assess the effectiveness of a scabies control program in reducing the prevalence of scabies in urban madrasas in Bangladesh (Weigl, 2018). The authors performed a controlled trial involving four intervention madrasahs (total number of students 2359) and four control madrasahs (total number of students 2465) in the Dhaka metropolitan area. In addition to mass treatment by $5 \%$ permethrin cream, interventions were carried out, including daily monitoring of students for five key personal hygiene practices, weekly 10-minute scabies health education classes, provision of simple and inexpensive products to students. The authors noted a reduction varying from $56 \%$ and $12 \%$ depending on the existence or not of an intervention.

In our study, while treatment and conventional hygiene measures were recommended, we did not carry out formal training for residents on the hygiene measures to be adopted. We believe that this type of intervention could have significantly improved the cure rate. The difficulty of managing scabies in closed communities, in particular Koranic schools, has already been highlighted (Laing et al., 2017). Both the intake of ivermectin and the application of benzyl benzoate were supervised by those responsible for the "daara". Compliance was better for ivermectin, while for benzyl benzoate, the absence of running water could be a limiting factor; residents were asked to shower with soap and water before applying the product. Ivermectin has been shown to be effective in both the management and prevention of outbreaks of scabies. This was very well demonstrated by Josef A I Weigl in 2017 for the occurrence of scabies's outbreaks in three schools in Ploen County in Germany (Lawrence et al., 2005). Mass treatment, home visits in index cases, and post-exposure prophylaxis (PEP) with ivermectin according to the characteristics of the epidemic have led to the eradication of scabies. The context is different in our study, but this experience can be adapted to the Koranic schools. Concerning the side effects, they were more common in the benzyl benzoate group than in the ivermectin group. Both irritative dermatitis and contact eczema are factors limiting the application of benzyl benzoate and could be mistaken for signs of persistent scabies. In a previous study, we had already demonstrated the superiority of benzyl benzoate over ivermectin in a hospital environment (Ly et al., 2009).

Our hypotheses concerning the low cure rate found in our study are as follows: long duration of evolution, severe forms of scabies, overcrowding, and low level of hygiene in some cases. In fact, $62 \%(n=28)$ showered once or twice a week, while 17 had more than two showers per week. In addition, there was overcrowding, with the number of people per room exceeding 10 in $70 \%$ of cases. Thus, we found an association between the rate of healing and the number of people in the room.

In addition, before our study, scabies was endemic since in one of the "daaras", the evolution dated back more than one year with a long history of therapeutic interventions. Various treatments were used, including benzyl benzoate, which was, therefore, familiar to residents and school officials. Traditional herbal treatments such as Detarium microcarpum and Momardica charantia were also used by some residents for the treatment of scabies. But only affected patients were treated, and the accompanying measures (individual and collective hygiene, treatment of all residents) were not always followed. In these Koranic schools, the hygiene of the residents is not supervised by the parents but rather by the leaders of the Koranic schools, who were usually men and who were not used to ensuring the personal hygiene and clothing of the children. At 
home, this role is rather devolved to women, who take care of housework, clothing, and personal hygiene.

Among the Koranic schools that we visited, those administered by women were the cleanest and with only one case of scabies. In fact, in some Koranic schools, Koranic teachers are assisted by women called "Ndeye daara" literally the "mother of the Koranic school" who is in charge of children's personal hygiene and clothing as well as food. Treatment failure could be due, apart from poor compliance, to the severity of scabies, reinfestation, side effects of drugs such as irritative dermatitis, the signs of which may be mistaken for the persistence of scabies. In addition, allergic reactions to Sarcoptes scabei could be responsible for the persistent itching, interpreted as treatment failure.

Another factor that we have already mentioned is the possibility of resistance of Sarcoptes scabei to ivermectin. Indeed, studies have identified four different mechanisms that could potentially contribute to scabicide resistance, as follows: (I) voltage-gated sodium channels, (II) glutathione Stransferase (GST), (III) ATP binding cassette transporters, and (IV) ligand-dependent chloride channels (Laing et al., 2017). It is also important to note that the cure time can be very long, at one month. Ultimately, benzyl benzoate appeared to be more effective than ivermectin in the context of our study. This underlines the therapeutic difficulty of managing scabies in closed communities (Lawrence et al., 2005). The need for multiple MDAs (Mass Drug Administration), three to five rounds annually, is recommended to eradicate this neglected tropical disease is well demonstrated (Thomas et al., 2020). Recently, in a study conducted in some villages in the center of India, the authors have shown that the treatment by ivermectin is associated with a reduction of the prevalence of scabies. Indeed, the risk of scabies was reduced by $79 \%$ and $51 \%$ at the end of two and twelve months in villages where oral ivermectin was used, compared to villages where patients were referred to receive skin creams (Behera et al., 2021).

At the end of this study, we propose some recommendations for health authorities: conduct interventional epidemiology studies in Koranic schools for the treatment of scabies and other neglected tropical diseases. For treatment, offer either higher doses of ivermectin at $400 \mu \mathrm{g}$ per $\mathrm{Kg}$ of weight as a single dose or the combination of ivermectin at $200 \mu \mathrm{g}$ per $\mathrm{Kg}$ of weight and benzyl benzoate. These treatments must be repeated on D7 than on D14. In addition, repeated treatments during the year should be relevant. The other measures include the organization of feedback sessions with the health authorities (Ministry of Health) and Koranic school officials, a medical examination supported by a certificate stating from infestation before entering the school, and early recognition of the clinical signs of scabies and provision of personal washing facilities. Pictorial brochures for students, posters, and flyers developed in partnership with the association of koranic school's teachers.

\section{Conclusion}

Scabies is a neglected tropical disease, which is endemic in Koranic School with recurrent outbreaks. The prevalence is variable, and the optimal treatment should be determined. We compare benzoate benzyl and ivermectin by oral route. On day 14, benzyl benzoate was more effective than ivermectin, but the rate of healing was still low. Indeed, less than $25 \%$ of patients had improvement of pruritus and clinical signs. We found no association between treatment failure either with impetigo or treatment compliance. Moreover, there was no link between the failure of treatment and socio-demographic characteristics such as the number of showers per week and the number of residents per room. Further studies are needed with a higher number of patients and different treatment regimens to provide definitive conclusions. In addition, a collaboration between medical authorities and the koranic school teachers' association would provide a good framework for interpreting interventional epidemiology.

\section{Declaration of Conflicting Interest}

The authors declare no conflict of interest.

\section{Funding}

This study was funded by CEA-SAMEF (centre d'excellence Africain de la santé Mére -enfant), the project /funding number was P 00017/2017.

Acknowledgment

We would like to thank Professor Roderick Hay for proofreading the manuscript. Also, acknowledgment to Astou Diouf Kebe, Fatou Gueye Diagne, Hasnae Mansouri, Foued El Fekki, Tdaha Tagmouti, Khady Diouf, Bassirou Dieye, Ndeye Beye Ngo, Ahmed Diagne, Ibrahima Sall, 
Assane Ndiaye, Fatoumata Kounta, Filly Kone, Ndeye Arame Niang, and Amina Diallo.

\section{Author Contributions}

F Ly wrote the article, conducted the study, supervised all the data collection in the koranic schools. A Faye, I Wone, and A Tall Dia supervised the protocol design. B Faye and Lelo $S$ are the parasitologists who collected all data. Koundio $\mathrm{A}$ and Toure $\mathrm{A} \mathrm{O}$ are hematologists who collected blood test data. Deh A, Ndiaye M Tene Diouf Astou and Gueye Diagne Fatou collected data.

\section{Author Biographies}

Ly Fatimata, MD, MSC, is Professor at the University Cheikh Anta Diop of Dakar and Dermatologist at the Institut d'Hygiène Sociale Dakar, Senegal.

Faye Adama, $P h D$, is Professor in the Department of Public Health at the University Cheikh Anta Diop of Dakar, Senegal.

Wone Issa, MD, MSC, is Professor in the Department of Public Health at the University Assane Seck of Ziguinchor Senegal.

Lelo Souleye MD, MSC, is a Lecturer in the Department of Parasitology-Mycology, University Cheikh Anta Diop, Dakar, Senegal.

Diouf Astou, MD, is a Dermatologist at the Institut d'Hygiène Sociale de Dakar, Senegal.

Koundio Abou, MD, is a Biologist in the Laboratory of Hematology, National Teaching Hospital Aristide Le Dantec, Dakar, Senegal.

Ndiaye Diop Mame Tene, MD, is a Dermatologist at the Institut d'Hygiène Sociale de Dakar, Senegal.

Gueye Diagne Fatou, $M D$, is a Dermatologist at the Institut d'Hygiène Sociale de Dakar, Senegal.

Deh Aminata, $M D$, is a Dermatologist at the Institut d'Hygiène Sociale de Dakar, Senegal.

Faye Babacar, $P h D$, is Professor in the Department of Parasitology-Mycology, University Cheikh Anta Diop, Dakar, Senegal.

Toure Fall Awa Oumar, $P h D$, is a Professor at the University Cheikh Anta Diop of Dakar and Hematologist in Laboratory of Hematology, National Teaching Hospital Aristide Le Dantec, Dakar, Senegal.

Mahe Antoine, MD, is Professor at the University Strasbourg, France and Dermatologist in the Hopital Louis Pasteur Hospital, Colmar, France.

Tall Dia Anta is Professor of Public Health at ISED (Institut Sante et Développement), Mbour, Senegal.

\section{References}

Behera, P., Munshi, H., Kalkonde, Y., Deshmukh, M., \& Bang, A. (2021). Control of scabies in a tribal community using mass screening and treatment with oral ivermectin -A cluster randomized controlled trial in Gadchiroli, India. PLoS Neglected Tropical Diseases, 15(4), e0009330. http://10.1371/journal.pntd.0009330

Cnltp. (2018). Retrieved from http://cnltp.org/rapport/carto graphieaimprimerJuin\%25\%2020\%202014.pdf. del Giudice, P., Chosidow, O., \& Caumes, E. (2003). Ivermectin in dermatology. Journal of Drugs in Dermatology: JDD, 2(1), 13-21.

Gwee, A., Duffull, S., Zhu, X., Tong, S. Y., Cranswick, N., McWhinney, B., . . . Steer, A. C. (2020). Population pharmacokinetics of ivermectin for the treatment of scabies in Indigenous Australian children. PLoS Neglected Tropical Diseases, 14(12), e0008886. https://doi.org/10.1371/journal.pntd.0008886

Karimkhani, C., Colombara, D. V., Drucker, A. M., Norton, S. A., Hay, R., Engelman, D., . . . Dellavalle, R. P. (2017). The global burden of scabies: A cross-sectional analysis from the Global Burden of Disease Study 2015. The Lancet Infectious Diseases, 17(12), 12471254. https://doi.org/10.1016/S1473-3099(17)30483-8

Kaur, H., Shekhar, N., Sharma, S., Sarma, P., Prakash, A., \& Medhi, B. (2021). Ivermectin as a potential drug for the treatment of COVID-19: an in-sync review with clinical and computational attributes. Pharmacological Reports, 1-14. https://doi.org/10.1007/s43440-02000195-y

Laing, R., Gillan, V., \& Devaney, E. (2017). Ivermectin - Old drug, new tricks? Trends in Parasitology, 33(6), 463472. http://10.1016/j.pt.2017.02.004

Lawrence, G., Leafasia, J., Sheridan, J., Hills, S., Wate, J., Wate, C., . . Purdie, D. (2005). Control of scabies, skin sores and haematuria in children in the Solomon Islands: Another role for ivermectin. Bulletin of World Health Organization, 83(1), 34-42.

Lemoine, A., \& Tounian, P. (2020). Childhood anemia and iron deficiency in sub-Saharan Africa-risk factors and prevention: A review. Archives de Pédiatrie. https://doi.org/10.1016/j.arcped.2020.08.004

Lipton, R., Schwedt, T., \& Friedman, B. (2016). GBD 2015 Disease and Injury Incidence and Prevalence Collaborators. Global, regional, and national incidence, prevalence, and years lived with disability for 310 diseases and injuries, 1990-2015: A systematic analysis for the Global Burden of Disease Study 2015. Lancet, 5; 388 (10053): 1545-602. https://doi.org/10. 1016/s0140-6736(16)31678-6

Ly, F., Caumes, E., Ndaw, C. A., Ndiaye, B., \& Mahé, A. (2009). Ivermectin versus benzyl benzoate applied once or twice to treat human scabies in Dakar, Senegal: A randomized controlled trial. Bulletin of World Health Organization, 87(6), 424-430. http://10.2471/blt.08.052 308

Navarro, M., Camprubí, D., Requena-Méndez, A., Buonfrate, D., Giorli, G., Kamgno, J., . . Krolewiecki, A. (2020). Safety of high-dose ivermectin: A systematic review and meta-analysis. Journal of Antimicrobial Chemotheraphy, 75(4), 827-834. http://10.1093/jac/ dkz524

Palmeirim, M. S., Hürlimann, E., Knopp, S., Speich, B., Belizario, V., Jr., Joseph, S. A., . . Keiser, J. (2018). Efficacy and safety of co-administered ivermectin plus albendazole for treating soil-transmitted helminths: $A$ systematic review, meta-analysis and individual patient 
data analysis. PLoS Neglected Tropical Diseases, 12(4), e0006458. http://10.1371/journal.pntd.0006458

Romani, L., Whitfeld, M. J., Koroivueta, J., Kama, M., Wand, H., Tikoduadua, L., ... Steer, A. C. (2015). Mass drug administration for scabies control in a population with endemic disease. New England Journal of Medicine, 373(24), 2305-2313. http://10.1056/NEJM oa1500987

Strong, M., \& Johnstone, P. (2007). Interventions for treating scabies. Cochrane Database of Systematic Reviews, 2007(3), Cd000320. http://10.1002/14651 858.CD000320.pub2

Sule, H. M., \& Thacher, T. D. (2007). Comparison of ivermectin and benzyl benzoate lotion for scabies in Nigerian patients, American Journal of Tropical Medicine and Hygiene, 76(2), 392-395.

Talukder, K., Talukder, M. Q., Farooque, M. G., Khairul, M., Sharmin, F., Jerin, I., \& Rahman, M. A. (2013).
Controlling scabies in madrasahs (Islamic religious schools) in Bangladesh. Public Health, 127(1), 83-91. http://10.1016/j.puhe.2012.09.004

Thomas, C., Coates, S. J., Engelman, D., Chosidow, O., \& Chang, A. Y. (2020). Ectoparasites: Scabies. Journal of the American Academy of Dermatology, 82(3), 533548. https://doi.org/10.1016/j.jaad.2019.05.109

Weigl, J. A. (2018). Outbreaks of scabies in schools and use of ivermectin. Gesundheitswesen (Bundesverband der Arzte des Offentlichen Gesundheitsdienstes (Germany)), 80(4), 360-364. http://10.1055/s-0044101140

World Health Organization. (2017). Integrating neglected tropical diseases into global health and development: fourth WHO report on neglected tropical diseases. Geneva: World Health Organization

Cite this article as: Fatimata, L., Adama, F., Issa, W., Souleye, L., Astou, D., Abou, K., Tene, N. D. M., Fatou, G. D., Aminata, D., Babacar, F., Oumar, T. F. A., Antoine, M., \& Anta T. D. (2021). Scabies in Koranic schools in Dakar, Senegal: Comparison of two therapeutic modalities. Public Health of Indonesia, 7(4), 172-181. https://dx.doi.org/10.366 85/phi.v7i4.456 